\title{
Adult immunization policies in advanced economies: vaccination recommendations, financing, and vaccination coverage
}

\author{
Lauren A. Wu $\cdot$ Elisabeth Kanitz $\cdot$ Julie Crumly $\cdot$ \\ Fortunato D'Ancona • Raymond A. Strikas
}

Received: 28 June 2012/Revised: 16 November 2012/ Accepted: 29 November 2012/Published online: 25 January 2013

(C) The Author(s) 2013. This article is published with open access at Springerlink.com

\begin{abstract}
Objectives While many countries have robust child immunization programs and high child vaccination coverage, vaccination of adults has received less attention. The objective of this study was to describe the adult vaccination policies in developed countries.

Methods From 2010 to 2011, we conducted a survey of 33 advanced economies as defined by the International Monetary Fund. The survey asked about national recommendations for adults for 16 vaccines or vaccine components, funding mechanisms for recommended adult vaccines, and the availability of adult vaccination coverage estimates.
\end{abstract}

Electronic supplementary material The online version of this article (doi:10.1007/s00038-012-0438-x) contains supplementary material, which is available to authorized users.

\section{A. Wu ( $₫)$}

National Vaccine Program Office, U.S. Department of Health and Human Services, Washington, DC, USA

e-mail: lauren.wu@hhs.gov

E. Kanitz · F. D'Ancona

Reparto Malattie Infettive, Istituto Superiore di Sanità, Centro Nazionale di Epidemiologia, Sorveglianza e Promozione della Salute, Rome, Italy

J. Crumly

Health Communication and Marketing Group,

Health Communication and Technical Training Program,

Oak Ridge Institute for Science and Education,

Oak Ridge, TN, USA

\section{R. A. Strikas}

Immunization Services Division, National Center

for Immunization and Respiratory Diseases,

Centers for Disease Control and Prevention,

Atlanta, GA, USA
Results Thirty-one of $33(93.9 \%)$ advanced economies responded to the survey. Twelve of 31 (38.7\%) reported having a comprehensive adult immunization schedule. The total number of vaccines or vaccine components recommended for adults ranged from one to 15 with a median of 10 . Seasonal influenza $(n=30)$, tetanus $(n=28)$, pneumococcal polysaccharide $(n=27)$, and hepatitis $\mathrm{B}(n=27)$ were the most frequently recommended vaccines or components. Conclusions Approximately two-thirds of survey respondents do not have a comprehensive adult vaccine schedule, and most do not measure vaccination coverage. We found that a funding mechanism is available for most recommended adult vaccines.

Keywords Adult immunization - Vaccination policy · Vaccination coverage · Vaccine financing ·

Developed country · Advanced economy

\section{Introduction}

Vaccines are one of the most cost-effective strategies to prevent infectious diseases among children, adolescents, and adults. Globally, vaccination saves an estimated 2-3 million lives each year. (WHO and UNICEF 2005) Many developed countries have robust child vaccination programs, and initiatives, such as the Expanded Programme on Immunisation and the Global Alliance for Vaccines and Immunisation, are helping developing countries build childhood immunization infrastructures and introduce new vaccines. (Levine et al. 2011) In contrast to the importance placed on childhood vaccination, less attention has been paid to adult immunization, even in developed countries with strong public health infrastructures. (Advisory Council for the Elimination of Tuberculosis and Advisory 
Committee on Immunization Practices 1996; Lang et al. 2011; Levine et al. 2011).

Vaccinating adults against infectious diseases is important because adults can be carriers of infectious diseases to the susceptible, and immunity from childhood immunizations wanes with age, leading to disease outbreaks such as pertussis in the United States. (Zepp et al. 2011) Additionally, many vaccines are most effective among the healthy, and it is good clinical practice to vaccinate healthy adults before they develop chronic conditions that are contraindications for vaccination or make vaccines less effective. Some vaccine-preventable diseases can become more severe with increasing age. Some adults were not vaccinated as children. Last, with increasing globalization, more and more people travel across borders and are susceptible to infectious diseases that are not endemic in their home country.

Successful childhood vaccination programs contain policies recommending vaccination, effective funding mechanisms, and routine vaccination coverage assessment. To better understand adult vaccine policies, we conducted a survey in 2010-2011 of 33 advanced economies around the world as defined by the International Monetary Fund in 2009. (International Monetary Fund October 2009) We asked about adult vaccination schedules, vaccine recommendations, vaccine funding mechanisms, and vaccination coverage availability and estimates. We also investigated the associations of having adult vaccine policies in place with the population size, per capita gross domestic product (GDP), per capita expenditure on health, and out-of-pocket spending on health.

\section{Methods}

To understand the prior literature on vaccine recommendations and vaccine coverage for adults in developed countries, we performed a PubMed/MEDLINE and Internet search for adult vaccine schedules and/or recommendations. The majority of the literature presented influenza vaccination coverage, with a few papers presenting vaccination coverage for other vaccines such as pneumococcal, hepatitis B, and tetanus vaccines. (Bader and Egler 2004, 2009; Beytout et al. 2004; Blank et al. 2009; de Miguel 2006; del Corro et al. 2009; Gavazzi et al. 2007; Kwong et al. 2007; Leggat et al. 2009; Montrieux et al. 2002; Nielsen et al. 2009; Noakes et al. 2006; Pebody et al. 2008; Sammarco et al. 2004; Schenkel et al. 2008; Stuck et al. 2007; van Houdt et al. 2009) We were unable to identify published literature that discussed a comprehensive adult vaccine schedule and adult vaccine financing in developed countries. To determine the denominator, we used the International Monetary Fund's (2009) classification of advanced economies $(N=33)$. (International Monetary Fund October 2009) This definition includes two special administrative regions (SARs) (Hong Kong SAR and Taiwan Province of China), and 31 countriesin North America, Europe, and Asia (see Table 1 for list of advanced economies).

Instrument

In March-April 2010, we developed a survey instrument that included questions about the availability of an adult vaccine schedule, recommendations for adults to receive specific vaccines or be vaccinated against certain diseases

Table 1 Advanced economies surveyed, abbreviations, and validation of data, 2010, survey of adult vaccination policies in advanced economy countries

\begin{tabular}{|c|c|c|c|}
\hline Advanced economy & $\begin{array}{l}\text { Completed } \\
\text { survey }\end{array}$ & Abbreviation & $\begin{array}{l}\text { Validated } \\
\text { data }\end{array}$ \\
\hline Australia & $\mathrm{x}$ & AU & \\
\hline Austria & $\mathrm{x}$ & $\mathrm{AT}$ & \\
\hline Belgium & $\mathrm{x}$ & $\mathrm{BE}$ & $\mathrm{x}$ \\
\hline Canada & $\mathrm{x}$ & $\mathrm{CA}$ & \\
\hline Cyprus & $\mathrm{x}$ & $\mathrm{CY}$ & $\mathrm{x}$ \\
\hline Czech Republic & $\mathrm{x}$ & $\mathrm{CZ}$ & $\mathrm{x}$ \\
\hline Denmark & $\mathrm{x}$ & DK & $\mathrm{x}$ \\
\hline Finland & $\mathrm{x}$ & FI & \\
\hline France & $\mathrm{x}$ & FR & $\mathrm{x}$ \\
\hline Germany & $\mathrm{x}$ & GE & \\
\hline Greece & $\mathrm{x}$ & GR & $\mathrm{x}$ \\
\hline Hong Kong, SAR China & $\mathrm{x}$ & HK & \\
\hline Iceland & $\mathrm{x}$ & IC & \\
\hline Ireland & $\mathrm{x}$ & IR & $\mathrm{x}$ \\
\hline \multicolumn{4}{|l|}{ Israel } \\
\hline Italy & $\mathrm{x}$ & IT & $\mathrm{x}$ \\
\hline Japan & $\mathrm{x}$ & JP & \\
\hline Luxembourg & $\mathrm{x}$ & $\mathrm{LU}$ & \\
\hline Malta & $\mathrm{x}$ & MT & $\mathrm{x}$ \\
\hline Netherlands & $\mathrm{x}$ & NL & \\
\hline New Zealand & $\mathrm{x}$ & $\mathrm{NZ}$ & \\
\hline Norway & $\mathrm{x}$ & NO & $\mathrm{x}$ \\
\hline Portugal & $\mathrm{x}$ & PT & $\mathrm{x}$ \\
\hline Republic of Korea & $\mathrm{x}$ & $\mathrm{KO}$ & \\
\hline \multicolumn{4}{|l|}{ Singapore } \\
\hline Slovak Republic & $\mathrm{x}$ & SK & $\mathrm{x}$ \\
\hline Slovenia & $\mathrm{x}$ & SL & \\
\hline Spain & $\mathrm{x}$ & SP & $\mathrm{x}$ \\
\hline Sweden & $\mathrm{x}$ & SD & $\mathrm{x}$ \\
\hline Switzerland & $\mathrm{x}$ & SW & \\
\hline Taiwan, Province of China & $\mathrm{x}$ & TW & \\
\hline United Kingdom & $\mathrm{x}$ & UK & $\mathrm{x}$ \\
\hline United States & $\mathrm{x}$ & US & \\
\hline
\end{tabular}


[for 16 vaccines or vaccine components: diphtheria, Bacillus Calmette-Guérin (BCG), hepatitis B, hepatitis A, herpes zoster, human papillomavirus (HPV), measles, meningococcal, mumps, pertussis, poliomyelitis (polio), pneumococcal, rubella, seasonal influenza, tetanus, and varicella], vaccine financing for recommended adult vaccines (public or private as applicable), availability of vaccination coverage estimates among adults, and vaccination coverage for recommended adult vaccines. We asked about vaccine components because countries have different vaccine formulations and combinations, depending on disease epidemiology and products offered by vaccine manufacturers. For questions on availability of private funding, we asked if a legal requirement in the country or SAR for private insurance to pay for vaccination for one or more groups of adults was in place, and, if so, to indicate for which groups of adults (e.g., specific age groups, those with medical conditions, travelers, at-risk employees, the disabled). We also asked if countries recommended other vaccines against vaccine-preventable diseases for adults in addition to the 16 we specifically asked about.

The questionnaire was administered using two formats: a web-based survey and a Microsoft (MS) Word survey sent via email. The web-based survey was pilot tested in four advanced economy countries (France, Ireland, Italy, and United States) in May-June of 2010. After appropriate changes were made based on the pilot test results, the weband MS Word-based surveys were sent to vaccination policy contacts in each country and SAR in late June 2010.

\section{Data collection}

For the advanced economies in the European Union plus Norway and Iceland (22 countries), we collaborated with the Vaccine European New Integrated Collaboration Effort II (VENICE II) to implement the web-based survey in SurveyMonkey (SurveyMonkey.com, LLC). Representatives from the national ministry of health or related national organization responsible for vaccine policies were invited to complete the survey. For a full list of VENICE II country gatekeepers, please see http://venice.cineca.org/ participating_countries.html. For the non-VENICE II advanced economies, we worked with representatives from the Australia Department of Health and Aging; the Public Health Agency of Canada; The Department of Health Hong Kong; the National Institute of Infectious Disease, Japan; The Korea Centers for Disease Control and Prevention; the University of Otago in New Zealand; and the Taiwan Centers for Disease Control and Prevention. If invited participants did not respond, web searches of publicly available vaccine schedules and policies published by the national ministry of health were performed to fill data gaps.
VENICE II served as the data collectors and managers for the web-based survey, and responded to questions regarding the survey. Countries that completed the webbased survey were asked to validate their data by reviewing their responses and updating them as necessary. Data collection continued through February 2011. For the remaining 11 countries and SARs, we administered the MS Word-based survey via email that contained the same questions as the web-based survey. Data on seasonal influenza, hepatitis B, and HPV vaccines were available from published reports of recent VENICE II surveys in 2008, 2009, and 2010, respectively. (Dorleans et al. 2010; Mereckiene et al. 2008, 2010) For survey respondents that did not provide an estimate for vaccination coverage for hepatitis B, data from published reports were used to supplement the data. (Bader and Egler 2004; Nielsen et al. 2009; Schenkel et al. 2008; Schiller and Euler 2008; van Houdt et al. 2009).

\section{Analysis}

Data from the web- and MS Word-based surveys were aggregated and analyzed using MS Excel 2007. We calculated the total, mean, and median number of vaccines recommended for adults in each advanced economy. For each of the 16 vaccines or components, we examined the groups of adults for which vaccines were recommended, the availability and type of funding, the availability of vaccination coverage estimates, and vaccination coverage for recommended adult vaccines.

We also examined the relationships between adult vaccine policies and characteristics of the advanced economy using bivariate logistic regression analyses. Odds ratios (ORs) were calculated in SAS (SAS Institute Inc. 2008) using the Proc Logistic procedure. The outcomes examined were availability of a comprehensive adult vaccine schedule (yes/no), recommendations for any group of adult to receive vaccination for a particular vaccine or component (yes/no), availability of any funding (public or private) for a recommended adult vaccine or component (yes/no), and availability of a vaccination coverage estimate for a recommended adult vaccine or component (yes/no). Data for the predictor variables were gathered from the World Bank. (The World Bank 2010a, b, c, d) Predictor variables examined were population (as of 2009), GDP per capita (current \$US as of 2009), health expenditure per capita (current \$US as of 2009), and out-of-pocket health expenditure (\% of private expenditure on health as of 2009). For the outcome "Comprehensive Adult Immunization Schedule (yes/no)," one OR was calculated for each of the four continuous predictor variables. For the outcomes "Recommendation (yes/no)," "Any Funding (yes/ no)," and "Coverage Estimate Available (yes/no)," meta- 
analysis was used to produce pooled ORs. First, for each of the four predictor variables, ORs were calculated when data were sufficient for each of 16 vaccines. The separate vaccine ORs were pooled into one OR for each predictor/ outcome combination using the $\mathrm{R}$ meta-analysis package named metafor. (Viechtbauer 2010).

The coauthors of this study, except for J. Crumly, also published the results of this survey for VENICE II member countries only in a separate paper. (Kanitz et al. 2012) The VENICE II consortium includes European countries not classified as advanced economies that are not included in the present analysis. The VENICE II only analysis also examines the types of vaccine components recommended, funding, and availability of coverage estimates for adult vaccines, but does not analyze the relationships between adult vaccine policies and characteristics of the countries. The current manuscript highlights findings from a group of countries and SARs with comparable economies, whereas the VENICE II only paper reports results for a group of countries sharing a common geographic location.

\section{Results}

Thirty-one of $33(93.9 \%)$ advanced economies responded to the survey; Israel and Singapore did not provide responses. The data were validated in 15 of 31 (48.4\%) advanced economies (Table 1). The age of adulthood for immunization purposes ranged from 15 (Spain) to 19 (Slovenia) years, with a median of 18 years. Twelve of 31 $(38.7 \%)$ advanced economies had a comprehensive adult vaccine schedule which describes the country or SAR's adult vaccine recommendations in one document. The total number of vaccines or vaccine components recommended for adults ranged from one to 15 with a median of 10 . Having a comprehensive adult vaccine schedule was associated with recommending more vaccines for adults [odds ratio $(\mathrm{OR})=1.38,95 \%$ confidence interval $(\mathrm{CI})$ : $1.007-1.891, p$ value 0.0452$]$.

\section{Descriptives}

Figure 1 shows the number of advanced economies that recommend vaccination for 16 vaccines or components for one or more groups of adults. This figure also indicates whether the recommendations are for all adults or for specific risk groups and travelers to disease-endemic areas. Specific risk groups include recommendations for particular age groups (e.g., older adults), adults with health conditions, at-risk employees including health care workers, and the disabled. For example, 30 (96.8\%) advanced economies recommend adults be vaccinated seasonally against influenza. Of these, two $(6.7 \%)$ recommend for all adults and $28(93.3 \%)$ recommend influenza vaccination for specific groups of adults.

The most frequently recommended vaccines for adults are seasonal influenza $(n=30)$, hepatitis $\mathrm{B}(n=27)$, pneumococcal $(n=27)$, tetanus $(n=26)$, and diphtheria $(n=26)$. The least frequently recommended vaccines for adults are Bacille Calmette-Guerin (BCG) $(n=10)$, mumps $(n=10)$, HPV $(n=5)$, and herpes zoster $(n=5)$. Most adult vaccines are recommended for specific risk groups and travelers, with the exceptions of tetanus, diphtheria, and pertussis.

Figure 2 shows the type of funding mechanism (public funding only, private funding only, public and private funding, or no funding) for recommended adult vaccines in advanced economies for the same 16 vaccines or components shown in Fig. 1. These funding mechanisms are for one or more groups of adults. Private funding indicates that a legal requirement for private health insurance to pay for vaccination for that particular vaccine or component is in place. As an example, seasonal influenza vaccine is financed through public funds only in 26 of 30 respondents $(86.7 \%)$ and through public and private funding in three $(10.0 \%)$ advanced economies. Although seasonal influenza vaccine is recommended for adults, no funding is provided for the vaccine in one $(3.3 \%)$ advanced economy. Most recommended adult vaccines are financed through public funds only. Pneumococcal $(26.3 \%)$, polio $(50.0 \%)$, varicella $(41.7 \%)$, pertussis $(40.0 \%)$, mumps $(25.0 \%)$, and HPV $(33.3 \%)$ vaccines have no funding mechanism for adults in $25 \%$ or greater of recommending advanced economies.

At least one advanced economy had a coverage estimate available for each of the 16 recommended adult vaccines or components for one or more groups of adults. Seasonal influenza vaccination coverage was the most commonly measured, with $29(96.7 \%)$ of advanced countries indicating a vaccination coverage estimate for adults is available. After seasonal influenza, the vaccines for which coverage was most commonly measured were hepatitis B $[n=11(42.3 \%)]$ and tetanus $[n=8(30.8 \%)]$. Six recommending advanced economies each had vaccination coverage estimates for diphtheria $(28.6 \%)$ and pneumococcal $(35.3 \%)$. Four recommending advanced economies had vaccination coverage estimates for hepatitis A (22.2\%). Three recommending advanced economies had a vaccination coverage estimate for the polio vaccine $(15.8 \%)$. One advanced economy had a vaccination coverage estimate available each for varicella (5.9\%), measles $(6.3 \%)$, mumps $(6.7 \%)$, rubella $(6.3 \%)$, meningococcal (6.7 \%), pertussis $(5.6 \%)$, BCG $(7.1 \%)$, HPV (16.7 \%), and herpes zoster $(25.0 \%)$. (Please note: the Australian Institute of Health and Welfare released the results of the 
Fig. 1 Advanced economies that recommend vaccines for adults, 2010, survey of adult vaccination policies in advanced economy countries $(n=30)$. Specific risk groups $=$ age, health condition, at-risk employee (including health care worker), disabled. Travelers are individuals that travel to disease-endemic areas

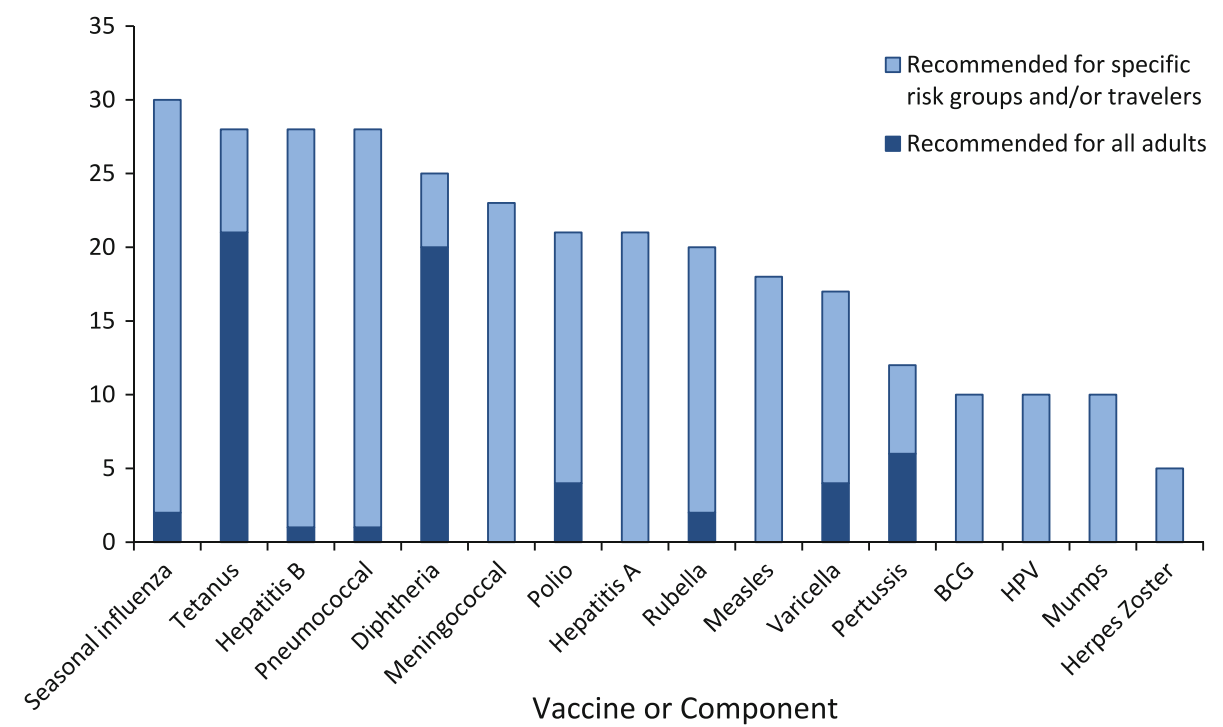

Fig. 2 Type of funding mechanisms for recommended adult vaccines, 2010, survey of adult vaccination policies in advanced economy countries $(n=30)$. Private

funding $=$ legal requirement for private health insurance to pay for vaccination

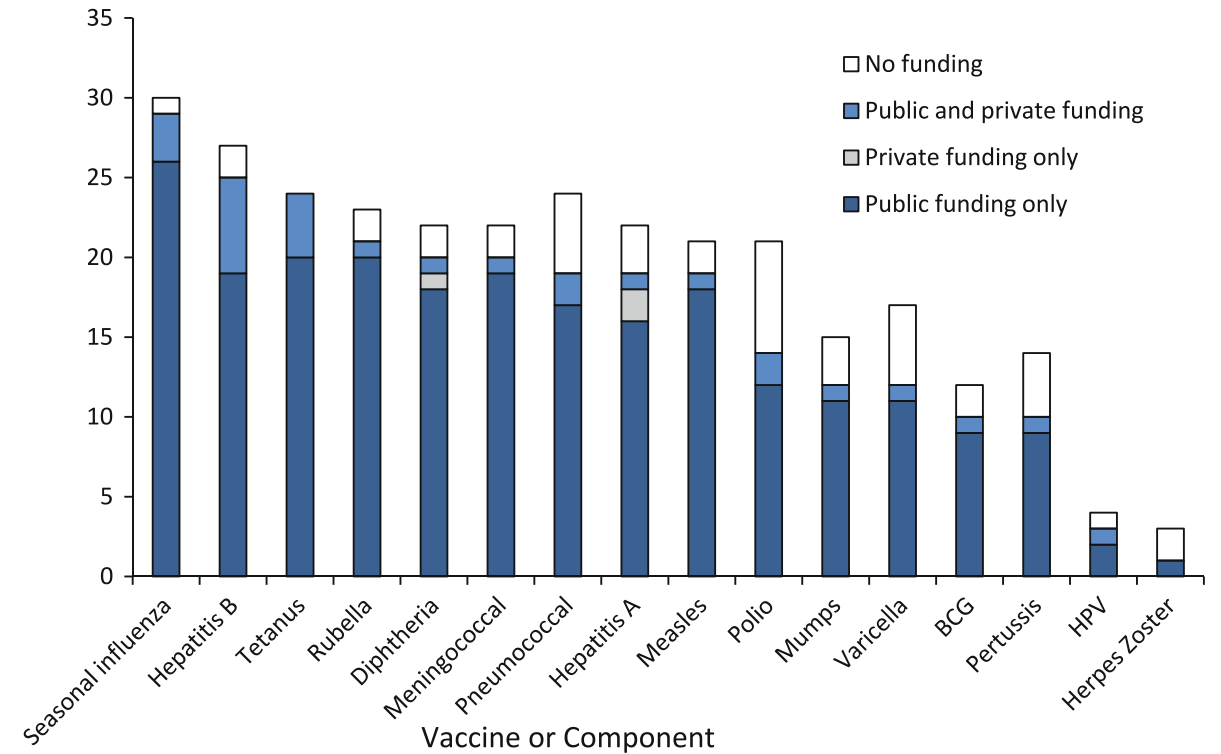

2009 Adult Vaccination Survey on March 3, 2011. To maintain comparability across the study period March 2010-February 2011, we do not include the results here.)

Figure 3 shows seasonal influenza vaccination coverage for adults $\geq 65$ years for the most recent influenza season for which data are available between 2006 and 2010 for 23 advanced economy countries (the data for Taiwan are for all adults $\geq 18$ years.). The Figure also shows the type of funding mechanism for seasonal influenza vaccine. Vaccination coverage ranged from $82 \%$ in the Netherlands to $25 \%$ in the Czech Republic. Coverage in Taiwan was $12 \%$. Despite not having any funding for seasonal influenza vaccine for adults, the coverage estimate for adults $\geq 65$ years in Norway $(50 \%)$ was higher than in seven advanced economies that do have a funding mechanism for the vaccine. The seasonal influenza vaccination coverage among adults $\geq 65$ years in these seven advanced economies was $31 \%$ in the Slovak Republic, $25 \%$ in the Czech Republic, $48 \%$ in Finland, $38 \%$ in Spain, $35 \%$ in Germany, $33 \%$ in Austria, and $29 \%$ in Slovenia.

Table 2 shows vaccination coverage estimates among adults for tetanus and hepatitis B vaccines for recommending advanced economies where data were available. In six advanced economies, tetanus vaccination coverage ranged from $47 \%$ among all adults ( $\geq 18$ years) in Canada to $71 \%$ among all adults ( $\geq 18$ years) in France. The tetanus coverage estimate was $6 \%$ among 16-24-year-olds in New Zealand and $95 \%$ among 25- 44-year-olds also in New Zealand. However, the estimates in New Zealand were based on a national serosurvey conducted among 597 individuals rather than vaccination coverage measurement. (Weir et al. 2009). 
Fig. 3 Seasonal influenza vaccination coverage estimates by advanced economy and type of funding for adults $\geq 65$ years, most recent from 2006 to 2010 $(n=23)^{\text {a }}$ Legal requirement for private health insurance to pay for vaccination ${ }^{\mathrm{b}}$ Data for New Zealand from a national serosurvey by the New Zealand Ministry of Health from Oct 2005 to Feb $2007, n=597^{\mathrm{c}}$ Data for Taiwan for all adults $\geq 18$ years. Source: Centers for Disease Control and Prevention (2010), Kwong et al. (2007), Mereckiene et al. (2008), Hajime Kamiya (Personal communication)

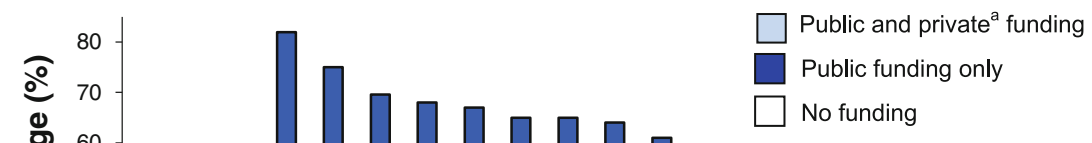

No funding
Hepatitis B vaccination coverage is shown by age groups and by risk groups of adults in Table 2. Among younger adults (from the adult age threshold up to 49 years), hepatitis $\mathrm{B}$ vaccination coverage ranged from $8 \%$ in Denmark to $58 \%$ in Canada. Among older adults ( $\geq 50$ years), there is one estimate for Germany at $33 \%$ coverage. Among health care workers, hepatitis B vaccination coverage ranged from $22 \%$ in Germany to $100 \%$ in the Czech Republic. For adults in behavioral risk groups, coverage ranged from $45 \%$ among intravenous drug users (IDU) in Finland to $62 \%$ in a sample of men who have sex with men, commercial sex workers, and IDU in the Netherlands.

\section{Regression analyses}

In Table 3, we show results of bivariate logistic regression analyses for the associations between advanced economy characteristics (population, GDP per capita, health expenditure per capita, and out-of-pocket health expenditure) and adult immunization strategies (adult immunization schedule, recommendation for a particular vaccine or component, any funding for a particular vaccine or component, and coverage estimate available for a particular vaccine or component). We adjusted the scale for population (to population per 5 million), GDP per capita (to GDP per capita per US \$5,000), and health expenditure per capita (to health expenditure per capita for US $\$ 1,000$ ) so the results would have a practical interpretation. Population per five million was associated with slightly increased odds of having a coverage estimate available. There was a marginally statistically significant reduced odds of having any funding available for the 16 vaccines or components as GDP per capita per US $\$ 5,000$ increases (pooled $\mathrm{OR}=0.94,95 \%$ CI $0.86-1.03)$. Both GDP per capita and health expenditure per capita were related to an increased probability of recommendation for vaccines, while increasing out-of-pocket health expenditure was associated with decreased odds of a recommendation for a vaccine and having a coverage estimate available (see Table 3). Recommendation for vaccination was related to having a comprehensive adult immunization schedule (pooled $\mathrm{OR}=1.73$, CI 1.30-2.29). Please note this finding is not reported in Table 3.

\section{Discussion}

This survey is the first to describe the range of adult vaccine strategies, policies, and funding sources in 31 advanced economies. Roughly one-third of the advanced economies have a comprehensive adult immunization schedule that summarizes their recommendations. We found a correlation between having a comprehensive adult immunization schedule and recommending more vaccines for adults. Although the confidence interval was wide, this finding could indicate that the importance of adult vaccination and the perception of the severity of vaccinepreventable diseases may vary from place to place.

We found the most frequently recommended vaccines for adults are seasonal influenza, tetanus, diphtheria, pneumococcal, and hepatitis B. These data are not surprising given that these five vaccines have been widely used for more than 30 years and were more often initially recommended for adults rather than children compared with other vaccines, such as varicella or polio. (Hinman and Orenstein 2007; Michel and Lang 2011; Poland et al. 2010; Roush and Murphy 2007) The least frequently recommended adult vaccines are BCG, HPV, mumps, and herpes zoster. BCG vaccination has varying efficacy against tuberculosis, especially among adults (ACIP 1990), and HPV and herpes zoster are relatively new vaccines. We 
Table 2 Tetanus and hepatitis B vaccination coverage estimates for adults in recommending advanced economies, 2010, survey of adult vaccination policies in advanced economy countries

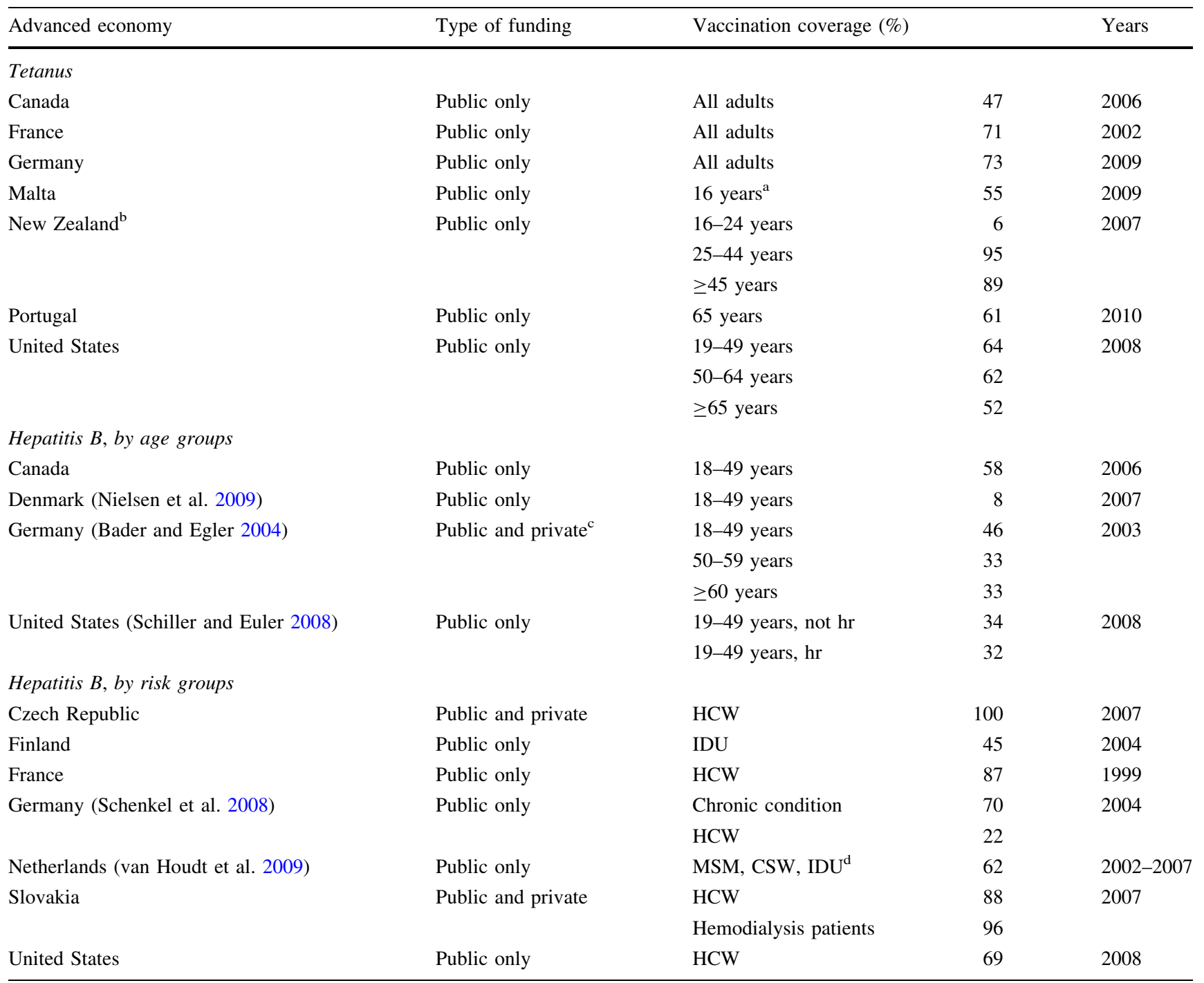

Norway has tetanus vaccination coverage for adults available but did not provide the estimate

$h r$ High risk, $H C W$ health care workers, IDU intravenous drug users, $M S M$ men who have sex with men, $C S W$ commercial sex workers

${ }^{\text {a }}$ Malta recommends a 5 th dose of tetanus vaccine at 16 years but the age of adulthood is 18 years

${ }^{\mathrm{b}}$ From a national serosurvey by the Ministry of Health from Oct 2005-Feb 2007, $n=597$

${ }^{c}$ Public and private funding indicates public funding is available and there is a legal requirement for private health insurance to pay for vaccination

${ }^{\mathrm{d}}$ From a sample of MSM, CSW, and IDU

Source Nielsen et al. (2009); Bader and Egler (2004); Schiller and Euler (2008); Schenkel et al. (2008); van Houdt et al. (2009)

also found most adult vaccines are recommended for specific groups of adults rather than recommended to all adults, consistent with cost effectiveness and indications for most of these vaccines. The age threshold of adults defined by the surveyed countries ranged from 15 to 19 years, which may affect the comparability of the survey results.

Lowering the financial barriers to receiving vaccines increases vaccine uptake. (The Community Guide 2008)
Therefore, an effective funding mechanism for adult vaccines is an important part of a comprehensive immunization strategy. Our results indicate increasing GDP per capita and increasing health expenditure per capita are associated with increased likelihood of a recommendation for a vaccine. We also found the majority of recommended adult vaccines are funded through public funds only. No international system of classifying health systems currently exists, and advanced economies may 
Table 3 Results of logistic regression analysis, 2010, survey of adult vaccination policies in advanced economy countries

\begin{tabular}{|c|c|c|c|c|}
\hline \multirow[t]{2}{*}{ Predictor $^{\mathrm{b}}$} & \multirow{2}{*}{$\begin{array}{l}\text { Odds ratio (95\% confidence interval) } \\
\text { Comprehensive adult } \\
\text { immunization schedule (yes/no) }\end{array}$} & \multicolumn{3}{|c|}{$\begin{array}{l}\text { Odds ratio (95\% confidence interval) for all } 16 \text { vaccines } \\
\text { or components }\end{array}$} \\
\hline & & $\begin{array}{l}\text { Recommendation } \\
\text { (yes/no) }\end{array}$ & $\begin{array}{l}\text { Any funding } \\
\text { (yes/no) }\end{array}$ & $\begin{array}{l}\text { Coverage estimate } \\
\text { available (yes/no) }\end{array}$ \\
\hline Per 5 million population & $1.08(0.96-1.22)$ & $1.01(0.98-1.03)$ & $1.00(0.95-1.06)$ & $1.05(1.00-1.09)$ \\
\hline GDP per capita per $\$ U S 5000$ & $0.92(0.71-1.18)$ & $1.10(1.02-1.19)$ & $0.94(0.86-1.03)$ & $0.96(0.86-1.06)$ \\
\hline Health expenditure per capita per $\$$ US 1000 & $1.00(0.64-1.57)$ & $1.33(1.16-1.53)$ & - & $1.06(0.88-1.27)$ \\
\hline Out of pocket health expenditure in percent ${ }^{\mathrm{c}}$ & $0.93(0.87-1.00)$ & $0.96(0.95-0.98)$ & $1.01(0.99-1.03)$ & $0.97(0.95-0.99)$ \\
\hline
\end{tabular}

${ }^{a}$ Diphtheria, Bacillus Calmette-Guérin (BCG), hepatitis B, hepatitis A, herpes zoster, human papillomavirus (HPV), measles, meningococcal, mumps, pertussis, poliomyelitis (polio), pneumococcal, rubella, seasonal influenza, tetanus, and varicella

b Data from the World Bank (see "Methods")

${ }^{c}$ Percent of total private expenditure on health

${ }^{\mathrm{d}}$ Bold: $p$ value for test statistic $<0.05$

define public and private funding differently. The type of funding available may also be limited to public only if the advanced economy has a centrally run national health care system, such as the National Health Service in the UK.

Most recommended adult vaccines have a source of funding, whether it is public or private, but it is important to note that pneumococcal, polio, pertussis, varicella, mumps, and HPV vaccines do not have a funding mechanism in more than $25 \%$ of recommending advanced economies. This lack of funding may be related to the length of time the vaccine has been recommended for adults, the epidemiology of disease burden, competing health interests, or the process of making vaccine recommendations in each advanced economy. In the survey, we asked for the year when a vaccine recommendation for adults was first made for each vaccine or component, but the majority of respondents did not provide a response. We did not have enough data to examine the relationship between funding mechanisms and health expenditure per capita. It may be that, as more government funds are spent on health in general, the need to fund adult vaccination is less perceived. However, this finding could be confounded by health care efficiency, as increased spending on health per capita does not necessarily correlate with improved quality of care. (Anderson and Frogner 2008) We did not ask about the processes of making vaccine recommendations in each advanced economy, which could be valuable in understanding the factors influencing adult vaccine policies. These could include deliberations by national or regional vaccine advisory committees, and how often vaccine policies are reviewed and updated. This information could be useful to understanding the decision-making process around vaccines and the relative importance of adult vaccination compared with other health priorities.

Vaccination coverage measurement is vital to evaluating immunization program progress. We found that, for all 16 vaccines or components except for seasonal influenza, the majority of recommending advanced economies do not have a coverage estimate available. The financial and structural resources needed for regular vaccination coverage measurement can be substantial, and adult vaccination may not be a health priority in many of these advanced economies.

We described vaccination coverage estimates for the three vaccines for which we have the most data: seasonal influenza, tetanus, and hepatitis B. Coverage rates vary substantially across similar age or risk groups. For seasonal influenza vaccine among adults 65 years and older, many advanced economies have reached coverage rates above $60 \%$, with a high of $82 \%$ in the Netherlands. In comparison, a number of advanced economies have coverage below $40 \%$ among the same age group. This may be related to the degree to which regular seasonal influenza vaccination is a long-standing part of preventive care.

We received responses from over $90 \%$ of the invited respondents, and while the data are based on self-report, these were validated in roughly half of the respondents. Some respondents expressed confusion about the meaning of a vaccine "recommendation," and we received some comments that a vaccine recommendation could be made by a range of groups, including the government or Ministry of Health and also by health care provider associations and vaccine manufacturers. Because this was a survey of adult vaccine policies, we asked about vaccines recommended by the government, Ministry of Health, or another official policy-making body in the advanced economy. We did not ask about the vaccine safety systems in these advanced economies, which is another important component of a vaccination program.

While ongoing vaccine uptake measurement can be resource intensive, guidelines to establishing such systems may be helpful for these advanced economies. A consensus 
statement issued by the European Union Geriatric Medicine Society and International Association of Gerontology and Geriatrics-European Union in 2009 advocated for strengthening and harmonizing vaccine strategies for adults 60 years and older at the European level. (Michel et al. 2009) Policies and programs are important not only for older adults, but for all adults to protect the well-being and health of the entire population. Advanced economies are experiencing aging of their populations, and with continuing improvements in medicine and the quality of life, public health will need to consider a shift in funding from childhood-based vaccination programs to "lifespan" programs. (Michel and Lang 2011; Poland et al. 2010).

The reduced effectiveness of some adult vaccines when compared with childhood vaccines may be a barrier to increased uptake. (Osterholm et al. 2012) As the number of available vaccines continues to increase, standards for vaccination strategies will ease the introduction of new vaccines into existing vaccination practices. An increasing role exists for non-traditional/non-medical home immunization providers, such as pharmacists and community vaccinators, and standards should include considerations for partnering with these health providers. (Postema and Breiman 2000).

\section{Conclusions}

We have demonstrated policies recommending vaccination for adults, funding mechanisms for adult vaccine administration, and routine adult vaccination coverage assessment vary and are often lacking in the countries with advanced economies surveyed. Newer vaccines are less likely to be recommended for adults than older ones. Funding of adult vaccination is associated with recommendations for adult vaccine use. Most recommended adult vaccines are funded with public funds alone. These elements of stable funding, standard recommendations, and routine vaccine coverage assessment are essential components of successful childhood immunization programs. For adult vaccination to be as effective as childhood programs, countries should strive to include them for their adult populations.

Acknowledgments The authors would like to thank the VENICE gatekeepers, contact persons, and survey respondents for their assistance with this research. This research was partially performed under an appointment to the U.S. Department of Health and Human Services, administered by the Oak Ridge Institute for Science and Education under contract number DE-AC05-06OR23100 between the U.S. Department of Energy and Oak Ridge Associated Universities.

Conflict of interest The authors have no financial or other conflicts to disclose.
Open Access This article is distributed under the terms of the Creative Commons Attribution License which permits any use, distribution, and reproduction in any medium, provided the original author(s) and the source are credited.

\section{References}

Advisory Committee on Immunization Practices (1990) Protection against viral hepatitis. Recommendations of the Immunization Practices Advisory Committee (ACIP). MMWR Recomm Rep 39:1-26

Advisory Council for the Elimination of Tuberculosis and Advisory Committee on Immunization Practices (1996) The role of BCG vaccine in the prevention and control of tuberculosis in the United States. A joint statement by the Advisory Council for the Elimination of Tuberculosis and the Advisory Committee on Immunization Practices. MMWR Recomm Rep 45:1-18

Anderson GF, Frogner BK (2008) Health spending in OECD countries: obtaining value per dollar. Health Aff (Millwood) 27:1718-1727. doi:10.1377/hlthaff.27.6.1718

Bader HM, Egler P (2004) Immunisation coverage in the adult workforce 2003. Utilisation of routine occupational health checks to ascertain vaccination coverage in employees. Bundesgesundheitsblatt Gesundheitsforschung Gesundheitsschutz 47:1204-1215. doi:10.1007/s00103-004-0942-0

Bayas JM, Izquierdo C, Ruiz L, Sintes X, Sousa D, Celorrio JM, Varona W, Carratala J, Nebot M, Batalla J, Sugranes S, Manzur A, Terren A, Garcia C, Clemente E, Rivera S, Justo I, Arevalo A, Salleras L, Dominguez A (2009) Validity of self-reported pneumococcal vaccination status in the elderly in Spain. Vaccine 27:4560-4564. doi:10.1016/j.vaccine.2009.05.057

Beytout J, Denis F, Giet R, Allaert FA (2004) Regional variations of adult population vaccinal status. Med Mal Infect 34:460-468

Blank PR, Schwenkglenks M, Szucs TD (2009) Vaccination coverage rates in eleven European countries during two consecutive influenza seasons. J Infect 58:446-458. doi:S0163-4453(09) 00115-7

Centers for Disease Control and Prevention (2010) Final estimates for 2009-2010 seasonal influenza and influenza A (H1N1) 2009 monovalent vaccination coverage-United States, August 2009 through May, 2010. Atlanta, GA: US Department of Health and Huma Services, CDC; 2010. Available at: http://www.cdc. gov/flu/professionals/vaccination/coverage_0910estimates.htm

de Miguel AG (2006) Strategies of vaccination for adult population in Spain in the actuality. An R Acad Nac Med (Madr) 123:175-194

del Corro MR, Vargas-Roman MI, Garcia RI, Prieto RG, de Miguel AG (2009) Tetanus vaccination in adult population: coverage, registration and compliance. Hum Vaccin 5:98-104. doi:6588

Dorleans F, Giambi C, Dematte L, Cotter S, Stefanoff P, Mereckiene J, O'Flanagan D, Lopalco PL, D'Ancona F, Levy-Bruhl D (2010) The current state of introduction of human papillomavirus vaccination into national immunisation schedules in Europe: first results of the VENICE2 2010 survey. Euro Surveill 15(47): 1-4. pii: 19730

Gavazzi G, Wazieres B, Lejeune B, Rothan-Tondeur M (2007) Influenza and pneumococcal vaccine coverages in geriatric health care settings in france. Gerontology 53:382-387. doi: 000105166

Hinman AR, Orenstein WA (2007) Adult immunization: what can we learn from the childhood immunization program? Clin Infect Dis 44:1532-1535. doi:CID51162 
International Monetary Fund (October 2009) World economic outlook database-WEO Groups and Aggregates Information. http://www.imf.org/external/pubs/ft/weo/2009/02/weodata/ groups.htm

Kanitz EE, Wu LA, Giambi C, Strikas RA, Levy-Bruhl D, Stefanoff P, Mereckiene J, Appelgren E, D'Ancona F (2012) Variation in adult vaccination policies across Europe: an overview from VENICE network on vaccine recommendations, funding and coverage. Vaccine 30:5222-5228. doi:S0264-410X(12)00851-1

Kwong JC, Rosella LC, Johansen H (2007) Trends in influenza vaccination in Canada, 1996/1997 to 2005. Health Rep 18:9-19

Lang PO, Govind S, Michel JP, Aspinall R, Mitchell WA (2011) Immunosenescence: implications for vaccination programmes in adults. Maturitas 68:322-330. doi:S0378-5122(11)00027-2

Leggat PA, Zwar NA, Hudson BJ (2009) Hepatitis B risks and immunisation coverage amongst Australians travelling to southeast Asia and east Asia. Travel Med Infect Dis 7:344-349. doi: S1477-8939(09)00058-1

Levine OS, Bloom DE, Cherian T, de Quadros C, Sow S, Wecker J, Duclos P, Greenwood B (2011) The future of immunisation policy, implementation, and financing. Lancet 378:439-448. doi: S0140-6736(11)60406-6

Mereckiene J, Cotter S, Nicoll A, Levy-Bruhl D, Ferro A, Tridente G, Zanoni G, Berra P, Salmaso S, O'Flanagan D, O Flanagan D (2008) National seasonal influenza vaccination survey in Europe, 2008. Euro Surveill 13(43):1-7. pii: 19017

Mereckiene J, Cotter S, Lopalco P, D'Ancona F, Levy-Bruhl D, Giambi C, Johansen K, Dematte L, Salmaso S, Stefanoff P, O'Flanagan D (2010) Hepatitis B immunisation programmes in European Union, Norway and Iceland: where we were in 2009? Vaccine 28:4470-4477. doi:S0264-410X(10)00543-8

Michel JP, Lang PO (2011) Promoting life course vaccination. Rejuvenation Res 14:75-81. doi:10.1089/rej.2010.1078

Michel JP, Chidiac C, Grubeck-Loebenstein B, Johnson RW, Lambert PH, Maggi S, Moulias R, Nicholson K, Werner H (2009) Advocating vaccination of adults aged 60 years and older in Western Europe: statement by the Joint Vaccine Working Group of the European Union Geriatric Medicine Society and the International Association of Gerontology and Geriatrics-European Region. Rejuvenation Res 12:127-135. doi:10.1089/rej. 2008.0813

Montrieux C, Collette G, Limme C, Seidel L, Albert A, Giet D (2002) Evaluation of tetanus vaccine coverage in rural society. Rev Med Liege 57:97-103

Nielsen US, Petersen E, Larsen CS (2009) Hepatitis B immunization coverage and risk behaviour among Danish travellers: are immunization strategies based on single journey itineraries rational? J Infect 59:353-359. doi:10.1016/j.jinf.2009.08.018

Noakes K, Pebody RG, Gungabissoon U, Stowe J, Miller E (2006) Pneumococcal polysaccharide vaccine uptake in England, 1989-2003, prior to the introduction of a vaccination programme for older adults. J Public Health (Oxf) 28:242-247. doi:fdl017

Osterholm MT, Kelley NS, Sommer A, Belongia EA (2012) Efficacy and effectiveness of influenza vaccines: a systematic review and meta-analysis. Lancet Infect Dis 12:36-44. doi:S1473-3099(11) 70295-X

Pebody RG, Hippisley-Cox J, Harcourt S, Pringle M, Painter M, Smith G (2008) Uptake of pneumococcal polysaccharide vaccine in at-risk populations in England and Wales 1999-2005. Epidemiol Infect 136:360-369. doi:S0950268807008436

Personal communication with Hajime Kamiya, Research/Medical Officer at the Japan National Institute of Infectious Diseases. 16 April 2010
Poland GA, Belmin J, Langley J, Michel JP, Van Damme P, Wicker S (2010) A global prescription for adult immunization: time is catching up with us. Vaccine 28:7137-7139. doi:S0264-410X (10)01355-1

Postema AS, Breiman RF (2000) Adult immunization programs in nontraditional settings: quality standards and guidance for program evaluation. MMWR Recomm Rep 49:1-13

Roush SW, Murphy TV (2007) Historical comparisons of morbidity and mortality for vaccine-preventable diseases in the United States. JAMA 298:2155-2163. doi:298/18/2155

Sammarco S, Ciofi degli Atti ML, Binkin N, D'Argenio P, Bella A (2004) Vaccine coverage survey of the elderly in 11 Italian regions. Ann Ig 16:701-708

Schenkel K, Radun D, Bremer V, Bocter N, Hamouda O (2008) Viral hepatitis in Germany: poor vaccination coverage and little knowledge about transmission in target groups. BMC Public Health 8:132. doi:10.1186/1471-2458-8-132

Schiller J, Euler G (2008) Vaccination coverage estimates from the National Health Interview Survey: United States, 2008. Centers for Disease Control and Prevention. http://www.cdc.gov/nchs/ data/hestat/vaccine_coverage.htm. Accessed 8 March 2010

Stuck AE, Kharicha K, Dapp U, Anders J, von Renteln-Kruse W, Meier-Baumgartner HP, Harari D, Swift CG, Ivanova K, Egger M, Gillmann G, Higa J, Beck JC, Iliffe S (2007) Development, feasibility and performance of a health risk appraisal questionnaire for older persons. BMC Med Res Methodol 7:1. doi: 1471-2288-7-1

The Community Guide (October 2008) Universally recommended vaccinations: reducing client out-of-pocket costs for vaccinations (abbreviated). www.thecommunityguide.org/vaccines/universally/ clientoutofpocketcosts.html

The World Bank (2010a) GDP per capital (current US\$) table. http://data.worldbank.org/indicator/NY.GDP.PCAP.CD

The World Bank (2010b) Health expenditure per capita (current US\$) table. http://data.worldbank.org/indicator/SH.XPD.PCAP

The World Bank (2010c) Out-of-pocket health expenditure (\% of private expenditure of health) table. http://data.worldbank.org/ indicator/SH.XPD.OOPC.ZS

The World Bank (2010d) Population total table. http://data.worldbank. org/indicator/SP.POP.TOTL

van Houdt R, Koedijk FD, Bruisten SM, Coul EL, Heijnen ML, Waldhober Q, Veldhuijzen IK, Richardus JH, Schutten M, van Doornum GJ, de Man RA, Hahne SJ, Coutinho RA, Boot HJ (2009) Hepatitis B vaccination targeted at behavioural risk groups in the Netherlands: does it work? Vaccine 27:3530-3535. doi:10.1016/j.vaccine.2009.03.072

Viechtbauer W (2010) Conducting meta-analyses in $\mathrm{R}$ with the metafor package. J Stat Softw 36:1-48

Weir R, Jennings L, Young S, Brunton C, Murdoch D (2009) National serosurvey of vaccine preventable diseases. Ministry of Health, Wellington

World Health Organization (WHO) and United Nations Children's Fund (UNICEF) (2005) Global Immunization vision and strategy, 2006-2015. World Health Organization and United Nations Children's Fund, Geneva

Zepp F, Heininger U, Mertsola J, Bernatowska E, Guiso N, Roord J, Tozzi AE, Van Damme P (2011) Rationale for pertussis booster vaccination throughout life in Europe. Lancet Infect Dis 11:557-570. doi:S1473-3099(11)70007-X 